\title{
TRADE AND SERVICE SECTOR DEVELOPMENT IN THE RURAL SOUTH: THE CASE OF THE TENNESSEE-TOMBIGBEE CORRIDOR
}

\author{
Robert A. Bohm, Henry W. Herzog Jr. and Alan M. Schlottmann*
}

\section{Introduction}

The trade and service industries have demonstrated significant growth in recent years. For instance, between 1977 and 1982, retail and wholesale industry sales increased by 49 and 59 percent respectively at the national level. On the other hand, the fastest growth in receipts over the period was in service industries, which increased by 89 percent. In this respect, it is interesting to note that the South led all regions in the rate of service industry growth, with receipts up 102 percent (U.S. Bureau of the Census, 1985).

Accompanying this trend has been a significant redirection of trade and service sector employment toward small metropolitan areas and nonmetropolitan (rural) areas. ${ }^{1}$ However, such an area redistribution has failed to reach many of our most rural, low income counties (a significant number of which are located in the South).

The purpose of this study is to develop an econometric methodology for identifying trade and service sectors at the county level that possess "development potential," that is, appear to be underdeveloped relative to a complete array of local socio-economic conditions. ${ }^{2}$ In this paper the method is applied to counties within the Tennessee-Tombigbee Corridor (defined below). On the other hand, the methodology is equally applicable to other multi-county regions of the country, and particularly in situations where state and local planners are asked to make specific recommendations on the preferred industrial composition of a more general trade and/or service development strategy.

After defining the Tennessee-Tombigbee Corridor, the trade and service sector location

\footnotetext{
*Professors of Economics, The University of Tennessee, Knoxville. Support for this study was provided by the Mobile District of the U.S. Army Corps of Engineers. In this respect, the authors would like to thank Al Galdis for helpful comments and suggestions on our technical report upon which this paper is based. The paper also benefited from comments of two referees.
}

decision is examined in terms of both intraand extra-county location determinants to include local demand, agglomeration economies and interindustry linkages, as well as transportation access and demand/supply potential within multicounty trade areas. Two models of individual trade and service seetor activity are then described and estimated in the following section. Based upon these econometric estimates, criteria developed for the selection of counties/sectors with "development potential" are both defined and applied to the Tennessee Tombigbee Corridor. Conclusions for the study follow.

\section{The Tennessee-Tombigbee Corridor}

The Tennessee-Tombigbee Corridor includes 51 counties and spans four states: Alabama, Mississippi, Tennessee and Kentucky. It roughly corresponds to the route of the U.S. Army Corps of Engineers Tennessee-Tombigbee Waterway Project, and stretches from Mobile, Alabama to Paducah, Kentucky. A map of this region is presented in Figure 1.

The majority of the counties in the Corridor are rather small in terms of their 1980 populations. For example, 30 counties had a 1980 population of less than 25,000 with 12 of this group actually less than 15,000 . On the other hand, 33 counties in the Corridor experienced population growth between 1970 and 1980 at a rate greater than the national average of 11 percent.

Only 12 Corridor counties had 1982 percapita incomes at or above 75 percent of the national average. At the other end of the spectrum, 11 Corridor counties had incomes 40 percent or more below national parity. Within the corridor, higher incomes are generally positively associated with county population. For example, of the 12 "high income" counties, 10 had 1980 populations exceeding 50,000. Conversely, all 11 of the Corridor counties with very low percapita incomes had populations under 25,000.

Trade and service employment concentration varies considerably across the 51 Corridor 
Figure 1

THE TENNESSEE-TOMBIGBEE CORRIDOR
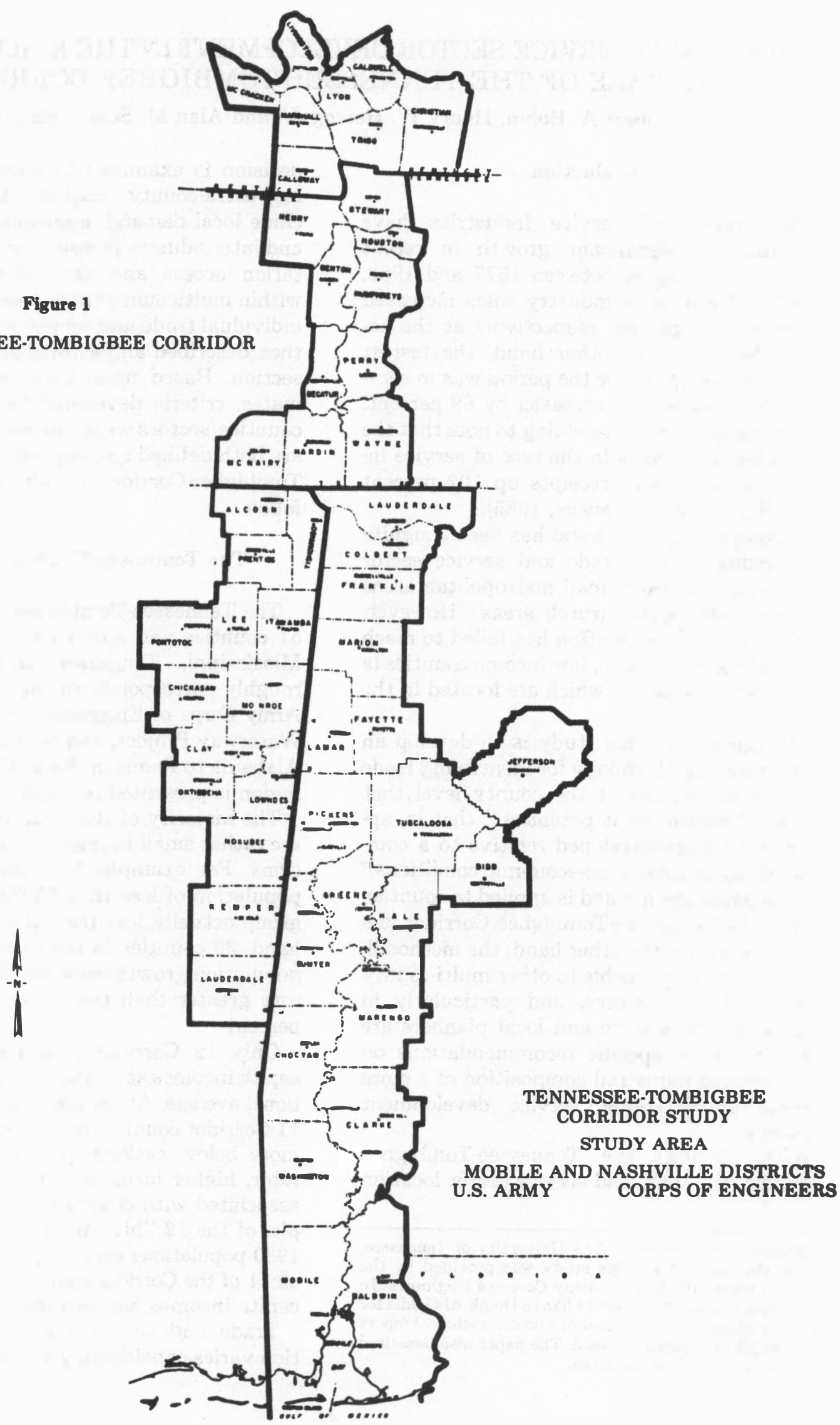
counties. $^{3}$ In 1982 , the percentage of county employment within the trades and services ranged from 14.8 to 78.9 percent, with such concentration equal to 60 percent at the national level. In most cases, counties with a low percentage of employment in trade and service industries have corresponding high concentrations of manufacturing employment. On the other hand, 17 Corridor counties have trade and service concentrations exceeding 50 percent. All but two of these fall into one of the two groups: (1) Large counties (population greater than 50,000 ) with well developed trade and service sectors, or (2) Small counties (population less than 25,000) with little alternative economic activity.

Interest in trade and service sector develop- ment is a relatively recent phenomenon, most likely triggered by the impressive growth of these industries (particularly services) at the national level, as well as the desire to obtain a share of this growth locally. Such growth has also awakened academic interest among regional scientists in location theory, and specifically, interest in the location decisions of industries (such as trades and services) that are neither transportation nor input oriented. In this respect, econometric models of local trade and service sector activity (for two-digit industries) have been developed by Bray (1980), and Olsen, Westley, Herzog, et al. (1977).

\section{Trade and Service Sector Location}

The location decisions of these trade and

Table 1

Variables Specific to Individual Sectors

\begin{tabular}{|c|c|c|c|}
\hline \multirow[b]{2}{*}{ Industry } & Age Group(s): & \multicolumn{2}{|c|}{ Closely Linked Sector(s: $)^{\mathbf{a}}$} \\
\hline & (1) $\quad(2)$ & (1) & \\
\hline 50 Wholesale Trade-Durable Goods & $18-64$ & 73 & \\
\hline 51 Wholesale Trade-Nondurable Goods & $18-64$ & 73 & \\
\hline 52 Building Materials, Hardware, Garden Supply, & & & \\
\hline and Mobile Home Dealers & $18-64$ & 73 & \\
\hline 53 General Merchandise Stores & $18-64$ & 73 & \\
\hline 54 Food Stores & $18-64$ & 73 & \\
\hline 55 Automotive Dealers and Gasoline Service & & & \\
\hline Stations & 18 and up & 75 & \\
\hline 56 Apparel and Accessory Stores & $18-64$ & 73 & \\
\hline 57 Furniture, Home Furnishings, and Equipment & & & \\
\hline Stores & $18-64$ & 73 & \\
\hline 58 Eating and Drinking Places & $18-64$ & 70 & \\
\hline 59 Miscellaneous Retail & $18-64$ & 73 & \\
\hline 60 Banking & $18-64$ & 73 & \\
\hline 61 Credit Agencies other than Banks & & 60 & 73 \\
\hline 62 Securities and Commodity Brokers, Dealers, & & & \\
\hline $\begin{array}{l}\text { Exchanges, and Services } \\
63 \text { Insurance }\end{array}$ & $18-64$ & $\begin{array}{l}60 \\
60\end{array}$ & 73 \\
\hline 64 Insurance Agents, Brokers, and Service & $18-64$ & 63 & \\
\hline 65 Real Estate & $18-64$ & 66 & \\
\hline 66 Combinations of Real Estate, Insurance, & & & \\
\hline Loans, Law Offices & $18-64$ & 65 & \\
\hline 67 Holding and Other Investment Offices & $18-64$ & 60 & \\
\hline 70 Hotels, Rooming Houses, Camps, and other & & & \\
\hline Lodging Places & & 58 & 65 \\
\hline 72 Personal Services & $18-64$ & 65 & \\
\hline 73 Business Services & $18-64$ & 65 & \\
\hline 75 Automotive Repair, Services, and Garages & 18 and up & 55 & \\
\hline 76 Miscellaneous Repair Services & $18-64$ & 57 & \\
\hline 78 Motion Pictures & $5-17$ & 65 & \\
\hline 79 Amusement and Recreation Services, except & & & \\
\hline Motion Pictures & $5-17$ & 65 & \\
\hline 80 Health Services & 65 and up & 65 & \\
\hline 81 Legal Services & $18-64$ & 60 & \\
\hline 82 Educational Services & $18-64$ & 65 & \\
\hline 83 Social Services & 65 and up & & \\
\hline 89 Miscellaneous Services & & 60 & 65 \\
\hline
\end{tabular}

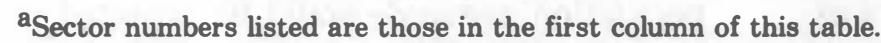


service industries (to include finance, insurance and real estate) were examined for 32 individual sectors defined by two-digit Standard Industrial Classification (SIC) codes between 50 and 89. Two of these industries, SIC 84 and SIC 86 (museums, galleries and zoological gardens; and membership organizations, respectively), were found to be of little significance in the Tennessee-Tombigbee Corridor and were deleted from the study.

For each of the remaining 30 trade or service sectors (see Table 1, p. 43), the number of establishments located within a Corridor county was related, based upon classical location theory, to a number of socio-economic conditions in that county, as well as to conditions elsewhere within a larger multicounty trade area. ${ }^{4}$ These conditions, or location factors, can be considered in two groups: (1) intracounty factors, and (2) extracounty factors.

\section{Intracounty Factors}

Intracounty factors that determine the location of specific trade and service industries include local demand conditions, agglomeration economies, and the presence of major input suppliers (interindustry linkages). Each will be discussed in turn.

Local demand conditions within each county shape both the magnitude and composition of local consumer purchases. Variables chosen to represent these effects within Corridor counties are: ${ }^{5}$

- median family income

- percent of families below the poverty line

- population

- population squared

- population density

- percent of population in specific age cohorts

- percent of housing units that are owneroccupied

- commuting ratio

- percent of population that are high school graduates

- unemployment rate

It is expected that the number of establishments in any two-digit trade or service sector in any Corridor county will increase with median family money income. However, to the extent that income may be an imperfect indicator of family welfare, the percent of families in each county below the poverty line has also been included within our analysis, and is ex- pected to show a negative association with the number of establishments.

The number of establishments in each trade or service sector should also increase with county population. However, to the extent that such population "effects" may not be linear, population squared is also used as a location factor. In addition, since the relative spacing of households within each county likely affects market area dimensions, population density is also considered. A final population variable-the percent in a specific age cohortwas selected for most two-digit sectors to identify and capture the relative size of the dominant consumer group within each county.

Since "owners" have different consumption habits than "renters," the percent of housing units (within each county) that are owneroccupied was included within the analysis. It is expected that establishments selling items such as building materials, hardware, garden supplies, etc. should increase in number in counties where this housing percentage is relatively large.

Intercounty commuting should also effect local demand. In order to capture this effect within our analyses, the ratio of jobs within each county to the number of employed residents was included as a location factor. Based upon this definition, ratios exceeding one imply net in-commuting while ratios less than unity imply net out-commuting. Thus, the number of establishments in any trade or service sector should be augmented as this ratio increases in magnitude, "ceteris paribus."

Since consumer tastes are expected to vary by educational level, the percent of each county's population that are high school graduates was also included as a determinant of trade and service sector activity. Finally, county unemployment rates were included to adjust for variation in labor market tightness (and resulting consumer expenditure effects) throughout the Tennessee-Tombigbee Corridor.

A second major category of intracounty location factors concerns agglomerative (concentration) tendencies of trade and service sectors in response to the consumer's demand for both variety of products (services) and ease of shopping. Such tendencies are readily observed in shopping malls and automobile "motor miles."6

Several location factors described abovesuch as population, population squared, and population density-would be expected to in- 
fluence the nature and magnitude of agglomeration economies available within Corridor counties. In addition, the relative concentration of trade activity within each county (percent wholesale and retail trade) was selected as a direct indicator of agglomerative tendency for each twodigit sector within the study. Based upon the nature of such "external economies," the number of establishments in each sector should be augmented by this indicator.

The final major category of intracounty location factors relates to interindustry linkages in input supply and other "complementary relationships" between sectors in the study. ${ }^{7}$ Such linkages, or relationships, are represented within our analyses by including as location factors the number of establishments (within the county) that are to some degree closely linked to each two-digit trade or service sector. For instance, the number of eating and drinking establishments within Corridor counties (SIC 58) should be augmented to some degree by increased numbers of hotels, rooming houses, camps and other lodging places (SIC 70) within the same counties.

\section{Extracounty Factors}

The number of establishments in each local trade and service sector is also affected by economic conditions outside the county, but within a multicounty trade area. Such "export" orientation of trade and service sectors has been examined in studies such as Olsen, Westley, Herzog, et al. (1977), and Bray (1980). Three variables were developed for each of the 51 Corridor counties to represent these conditions:

- number of miles to interstate interchange

- extracounty demand potential

- extracounty supply potential

Since extracounty demand for trade and service sector outputs is augmented by better access to the interstate highway system, the number of establishments within each sector and county should be negatively associated with the number of miles to an interstate interchange, "ceteris paribus."

Extracounty demand is positively related to purchasing power and negatively associated with driving time within each multicounty trade area. In order to represent these two opposing location factors, an extracounty de- mand potential for each Corridor county "i" was defined as

$$
\sum_{j \neq i} \frac{Y_{j}}{D_{i j}}
$$

where $Y_{j}$ is total income in county " $j$ ", $D_{i j}$ is the distance (miles) between population centroids of counties " $\mathrm{i}$ " and " $\mathrm{j}$ ", and the $\mathrm{i}$-th county's trading area is defined as all counties " $\mathrm{j}$ " for which $\mathrm{D}_{\mathrm{ij}} \leq 50 .{ }^{8}$ Given this definition, it is expected that establishments in county "i" should be augmented to some degree by increased extracounty demand potential.

On the other hand, the proximity of competing establishments within multicounty trade areas should diminish the number of establishments observed in each trade and service sector and Corridor county. Such proximity of sector " $k$ " to county " $i$ " can be represented within an extra-county supply potential defined as

$$
\sum_{j \neq i} \frac{E_{k j}}{D_{i j}},
$$

where $\mathrm{E}_{\mathrm{kj}}$ is the number of establishments in sector " $k$ " in county " $j$ ", $D_{i j}$ is the distance (miles) between population centroids of counties " $\mathrm{i}$ " and " $\mathrm{j}$ ", and the $\mathrm{i}$-th county's trading area is defined, as above, as all counties " $j$ " for which $\mathrm{D}_{\mathrm{ij}} \leq 50$.

\section{Models of Trade and Service Sector Activity}

Two econometric models were developed to examine the individual importance of the various location factors discussed above. For both models, the dependent variable is the number of establishments in a given two-digit trade or service sector at the county level. ${ }^{\circ}$ On the other hand, the models differ in both the location factors (independent variables) and counties included within the analysis.

\section{Model One}

The first econometric model is used to explain trade and service sector development on the basis of local (intracounty) socio-economic conditions. Thus, only location factors discussed above under the general headings of local de- 
mand conditions, agglomeration economies, and interindustry linkages were included as independent variables. Observations for this multivariate analysis comprise the 51 Tennessee Tombigbee Corridor counties plus an additional 52 counties contiguous to the Corridor. These additional counties provide a larger base line, or refrence region, for the subsequent analysis of development potential within the Corridor.

Individual regressions were run for each of 30 two-digit trade and service industries. Explanatory variables (local demand, agglomeration, and interindustry linkages) were equivalent across industries, with two exceptions. In this respect, variables specific to individual sectors were selected to represent: (1) particular age cohorts, and (2) particular highly linked industries. These variables are defined for each of the 30 trade and service sectors in Table 1. Based upon the information provided in the table, specific variables, for instance, for eating and drinking places (SIC 58), are related both to the percentage of county population within age cohort 18-64, and to the number of establishments within the county in Sector 70 (hotels, rooming houses, camps, and other lodging places).
Ordinary Least Squares (OLS) estimates of model one for the 30 two-digit trade and service sectors are provided in Table 2. For each of these sectors, signs shown are significant at the 10 percent level or better, and the adjusted $\mathrm{R}^{2}$ statistic exceeds .70.

Employing sector 52 (building materials, hardware, garden supply, and mobile home dealers) as an example, notice in Table 2 that four intracounty location factors are significant determinants of the number of establishments. Based upon the signs shown, such numbers increase both with county population and with the number of business service establishments located within the county (closely linked sector-see Table 1). On the other hand, notice that the attractiveness of population to this sector wanes to some degree as population increases (negative population squared term) and as density increases.

\section{Model Two}

The second econometric model is used to explain trade and service sector development on the basis of both intra- and extracounty socioeconomic conditions. Thus, this second model of trade and service sector activity

Determinants of Trade and Service Sector Activity in Corridor Counties: OLS Estimates ${ }^{a}$ (Intracounty Location Factors)

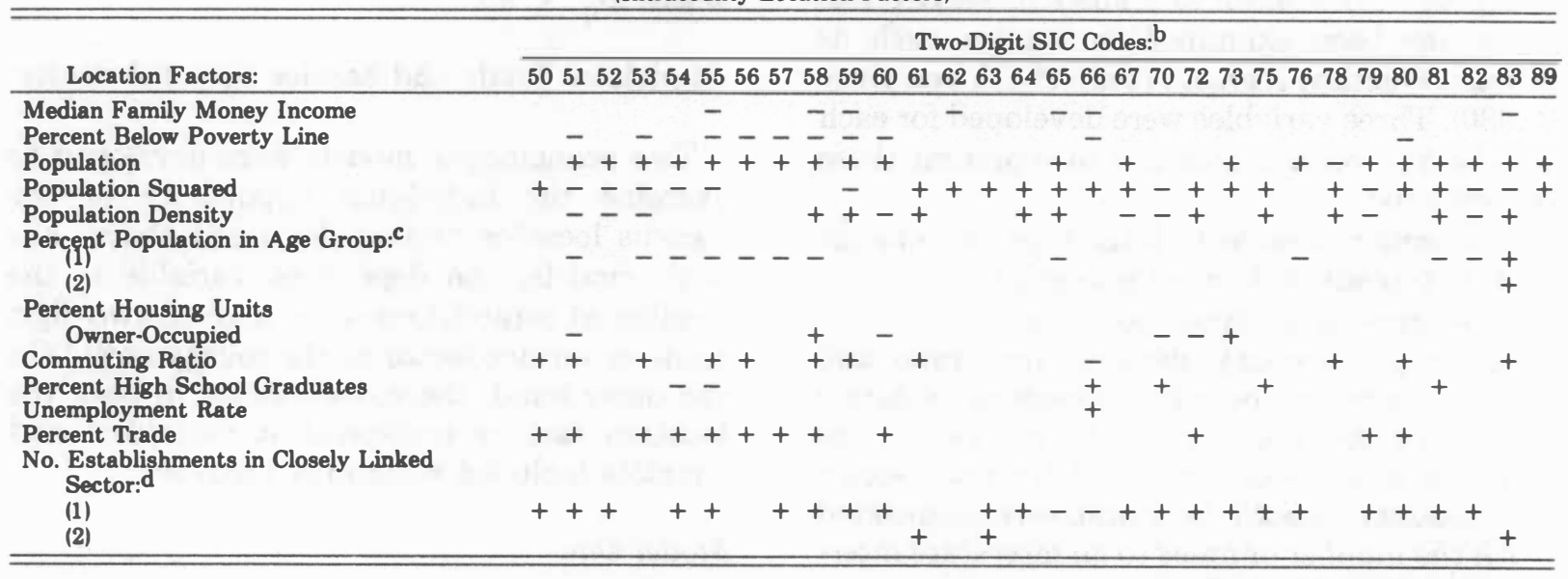

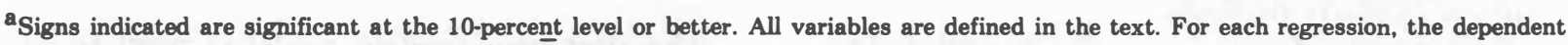
variable is the number of establishments, and $\bar{R}^{2}$ exceeds .70 .

bThese two-digit codes are defined in Table 1.

CThese age cohorts are defined, for each two-digit code, in Table 1.

dFor each twodigit code, these sectors are defined in Table 1. 
recognizes that trade areas are seldom confined to individual counties, and thus that development within Tennessee-Tombigbee Corridor counties is dependent upon demand and competing supply in adjacent counties (both within and without the Corridor).

In order to represent these extracounty effects, three additional location factors (independent variables) were considered along with the intracounty factors employed in model one. Defined above, these are: (1) miles to an interstate interchange, (2) extracounty demand potential, and (3) extracounty supply potential. Observations for this latter multivariate analysis are confined to the 51 Corridor counties, although (2) and (3) above are determined on the basis of the 103 counties considered by model one. ${ }^{10}$

OLS estimates of model two for the 30 twodigit trade and service sectors are provided in Table 3. Like Table 2, signs shown are significant at the 10 percent level or better, and the adjusted $\mathrm{R}^{2}$ statistic for each sector exceeds .70 .

Again employing sector 52 (building materials, hardware, garden supply, and mobile home dealers) as an example, notice in Table 3 that five intracounty and two extracounty location factors are significant determinants of the number of establishments. Thus, such establishments increase in number with county population (but at a decreasing rate), with the percentage of owner-occupied housing units, and with the number of business service establishments located within the county (closely linked sector-see Table 1). On the other hand, establishment numbers in SIC 52 are diminished by high population density, lengthy access to the interstate highway system, and by competing establishments in adjacent counties (extracounty supply potential)."

\section{Identifying Development Potential}

As stated at the outset, the purpose of the study has been to construct and apply a methodology for identifying trade and service sectors at the county level that possess "development potential," that is, appear to be underdeveloped relative to socioeconomic conditions throughout local market areas. Given estimates such as those in Tables 2 and 3, residuals from models one and two provide important information to this end. In this respect, positive residuals indicate development in excess of that "expected" on the basis of local (or extracounty) conditions, while negative residuals indicate the reverse, i.e., an apparent shortfall of development vis-a-vis such conditions.

While recognizing that specific residual patterns from the two models $[++,--,+-,-+]$

Determinants of Trade and Service Sector Activity in Corridor Counties: OLS Estimates" (Intra-and Extracounty Location Factors)

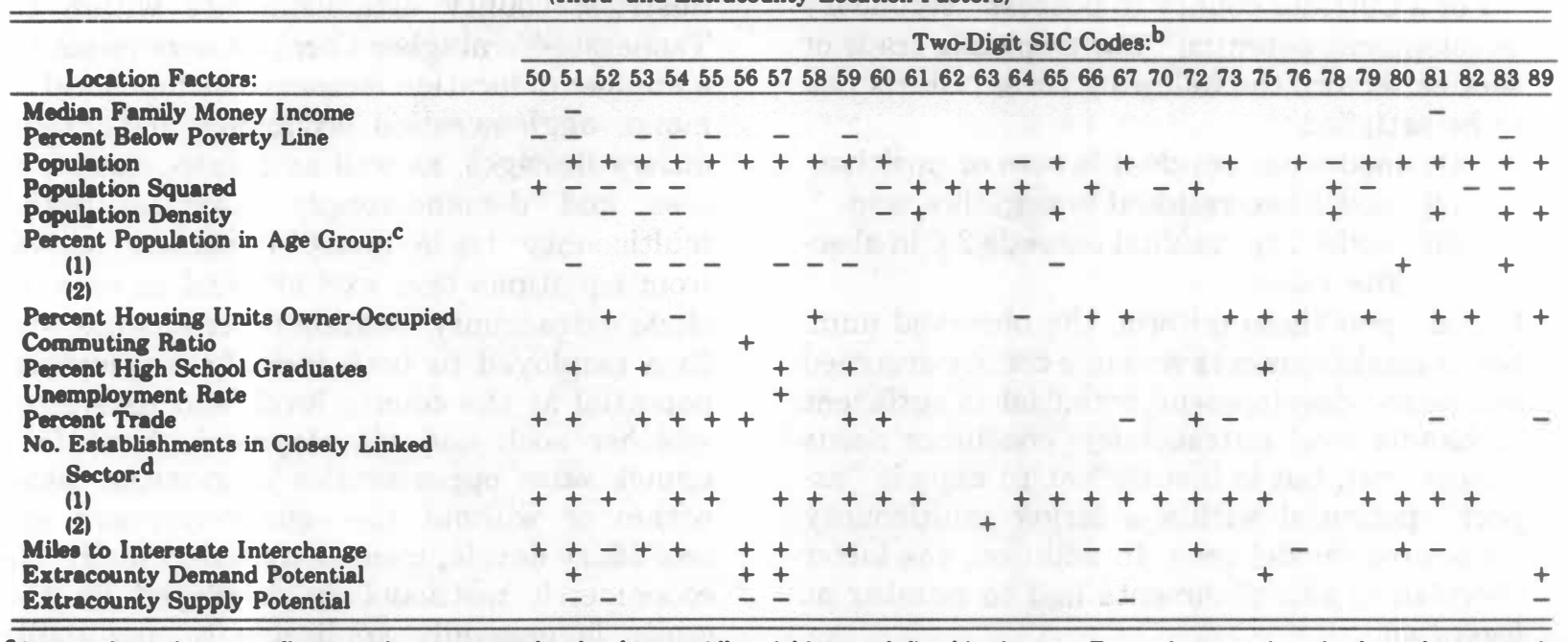

Gigns indicated are significant at the 10-percent level or better. All variables are defined in the text. For each regression, the dependent variable is the number of establishments, and $\bar{R}^{2}$ exceeds .70 .

Theee trodifit codes are defined in Table 1. CThese age cohorts are defined, for each two-digit code, in Table 1. dFor each twodigit code, these sectors are defined in Table 1. 
may be interpreted quite differently by individuals considering the preferred industrial composition of a local trade and service development plan, our recommendations for the 51 Tennessee-Tombigbee Corridor counties were based upon a two tier approach. ${ }^{12}$ Under such an approach, development potential was assigned as follows.

\section{Primary Development Potential}

For a Corridor county to possess "primary development potential" (for a specific trade or service sector), the following three criteria had to be satisfied:

(1) model one residual is negative,

(2) model two residual is negative, and

(3) model two residual exceeds 2.0 in absolute value.

Thus, the observed number of establishments must be less than the expected number re quired to meet local needs (based on a model emphasizing intracounty location factors). In addition, the observed number of establishments must also be less than the expected number required to meet potential demand within a larger multicounty trade area (based on a model which includes both intracounty and extracounty location factors). Finally, the latter shortfall, or deficiency, of establishments had to equal at least two. ${ }^{13}$

\section{Secondary Development Potential}

For a Corridor county to possess "secondary development potential" (for a specific trade or service sector), the following three criteria had to be satisfied:

(1) model one residual is zero or positive,

(2) model two residual is negative, and

(3) model two residual exceeds 2.0 in absolute value.

Based upon these criteria, the observed number of establishments within a county assigned secondary development potential is sufficient to handle local (intracounty) consumer needs (model one), but is insufficient to exploit "export" potential within a larger multicounty trade area (model two). In addition, the latter shortfall of establishments had to number at least two.

Implicit within these definitions is our belief that counties possessing primary development potential relative to a specific trade or service industry are better "bets" for the successful implantation of additional firms of that industry, than are other counties similarly identified on the basis of secondary potential. Based upon the criteria above, study results suggest significant trade and service industry development potential within the 51 county Tennessee Tombigbee Corridor. Primary development potential was indicated for 337 trade and service industry-county combinations (approximately 24 percent of the theoretical maximum of 1,377 potential combinations). ${ }^{14}$ In addition, the methodology identified an additional 36 trade and service industry-county combinations possessing secondary development potential. In general, development of one or more trade and service sectors was indicated for each county within the Corridor.

\section{Conclusions}

Although the trade and service industry has demonstrated both significant growth and areal deconcentration in recent years, such restructuring and redistribution of economic activity in this country has failed to reach many of our most rural, low income counties. In order to assist such counties, many of which are located in the South, a methodology was proposed to help identify local trade and service sectors that possess development potential, or otherwise appear underdeveloped vis-a-vis local socio-economic conditions.

For each of 30 two-digit trade and service industries, county establishments within the Tennessee-Tombigbee Corridor were related to a number of location factors to include local demand, agglomeration economies and interindustry linkages, as well as transportation access and demand/supply potential within multicounty trade areas. Residuals derived from equations that exclude, and in turn, include extracounty location determinants were then employed to both identify development potential at the county level, and to suggest whether such underdevelopment stems from unmet sales opportunities originating either within or without the county (primary and secondary development potential). Finally, the econometric methodology developed for this study is generally applicable to any multicounty region of the country. It is thought to be particularly useful in situations where state and local planners must formulate specific 
recommendations on the industrial composition of a local trade and/or service development strategy.

\section{FOOTNOTES}

${ }^{1}$ For an analysis of deconcentration trends among the trades in the U.S., see Morrill. A more general treatment of the services is to be found in Kutscher, Runyon, and Stanback et al

'The authors have also developed an alternative methodology (based upon classical location theory) for identifying manufacturing sectors with development potential at the county level. See Bohm, Herzog and Schlottmann.

'Based upon employment in Standard Industrial Classification (SIC) codes 50-89.

'For concise summaries of this literature, see Berry, Hoover and Giarratani, and Smith.

'Information for all variables chosen to represent location factors was obtained from U.S. Bureau of the Census, 1984a.

These agglomeration (concentration) economies are described in detail in Hoover and Giarratani. See especially pp. 108 and 109.

'See Hoover and Giarratani, pp. 256 and 257.

${ }^{8}$ For a comprehensive examination of potential (and gravity) concepts, see Isard, Chapter 11.

'Data on the number of establishments by two-digit SIC industry were obtained from state volumes of County Business Patterns, U.S. Bureau of the Census, 1984b. Establishments rather than employment were utilized as the dependent variable due to the significant number of cases where the latter information was not disclosed for individual counties/two-digit sectors. However, to the extent that variation in employment per establishment at the county level is also related to the intra- and extracounty variables summarized above, the identification of development potential (in the following section) may be made on the basis of residuals derived from either establishment or employment equations.

${ }^{10}$ See equations (1) and (2).

"Although certain location factors occasionally enter the models with perverse signs (for instance, median family money income), the majority of the significant variables shown in Tables 2 and 3 are consistent with a priori expectations.

${ }^{12}$ For example, an alternative approach to our own would assign significant development potential to specific sectors/counties where residuals from both models one and two are positive. An argument could be made for such an assignment that the pair of positive residuals indicates that the county is an important regional trade center for the specific commodity (sector), and as such could be further developed.

${ }^{13}$ This third constraint (which might vary by sector) permits the elimination of counties/sectors from a development plan on the basis of magnitude, rather than sign, of a residual. Note that residual size can also be employed to "rank" counties by development potential for a specific trade or service sector.

14Several of the 30 two-digit trade and service sectors (see Table 1) were combined for the identification of development potential throughout the Corridor. In this regard, SIC codes 63 and 64 were combined as were codes 65,66 and 67 . Thus, the total number of county-sector combinations is $1,377(51 \times 27)$.

Two caveats must be born in mind when employing our methodology. First, one should remember that the analysis is conducted at a fairly aggregate (two-digit) level. This means that some specific opportunities at a more detailed level (e.g., three or four digits) may be masked and hence omitted. Second, the identification of development potential for a specific industry-county combination does not represent a guarantee that subsequent investment will prove successful and profitable. Thus, any development opportunity identified by an analyst utilizing the above methodology should be subjected to a detailed marketing and financial feasibility study prior to any commitment to actual investment.

\section{REFERENCES}

Berry, Brian J. L. Geography of Market Centers and Retail Distribution, Englewood Cliffs, New Jersey: Prentice-Hall, Inc., 1967.

Bohm, Robert A., Henry W. Herzog Jr. and Alan M. Schlottmann. "Industrial Location in the TennesseeTombigbee Corridor," The Review of Regional Studies, Vol. 13, No. 1 (Winter, 1983), 28-37.

Bray, Larry G. "A Model of Local Sector Growth in the South," Unpublished doctoral dissertation, Department of Economics, The University of Tennessee, Knoxville, August, 1980.

Hoover, Edgar M. and Frank Giarratani. An Introduction to Regional Economics, New York: Alfred A. Knopf, 1984.

Isard, Walter. Methods of Regional Analysis: An Introduction to Regional Science, Cambridge, Massachusetts: The M.I.T. Press, 1960.

Kutscher, R. E. and J. A. Mark. "The Service-Producing Sector: Some Common Perceptions Reviewed," Monthly Labor Review, April, 1983, 21-24.

Morrill, Richard L. "Continuing Deconcentration Trends in Trade," Growth and Change, Vol. 13, No. 1 (January, 1982), 46-48.

Olsen, R. J., G. W. Westley H. W. Herzog Jr., et al. Multiregion: A Simulation-Forecasting Model of BEA Economic Area Population and Employment, Regional Studies Program, Energy Division, Oak Ridge National Laboratory, Oak Ridge, Tennessee (ORNL/RUS-25), October, 1977.

Runyon, H. "The Service Industries: Employment, Productivity, and Inflation," Business Economics, January 1985, 55-63.

Smith, David M. Industrial Location, An Economic Geographical Analysis, New York: John Wiley \& Sons, Inc., 1971.

Stanback, Thomas M. Jr. et al. Services: The New Economy, Totowa, New Jersey: Allanheld, Osmun, 1981.

U.S. Bureau of the Census. County and City Data Book, U.S. Department of Commerce, Washington, D.C., 1984a. . County Business Patterns, U.S. Department of Commerce, Washington, D.C., 1984b.

. Data User News, U.S. Department of Commerce, Washington, D.C., Vol. 20, No. 4 (April, 1985), 7. 